\title{
Altered adherence properties of a Streptococcus gordonii hppA (oligopeptide permease) mutant result from transcriptional effects on cshA adhesin gene expression
}

\author{
Roderick McNab† and Howard F. Jenkinson‡
}

Molecular Oral Biology Laboratory, Department of Oral Biology and Oral Pathology, University of Otago, PO Box 647, Dunedin, New Zealand
Author for correspondence: Howard F. Jenkinson. Tel: +44 117928 4304. Fax: +44 1179284428. e-mail: howard.jenkinson@bristol.ac.uk
Cell-surface polypeptide CshA (259 kDa) mediates multiple adherence interactions of Streptococcus gordonii. By generating a chromosomal cshA promoter ( $p$-cshA)-cat gene fusion and measuring both CAT enzyme activity and cat mRNA levels, it was shown that cshA is expressed maximally in cells in the late exponential phase of growth in batch culture. The expression of CAT enzyme activity from the p-cshA-cat promoter fusion was $28 \%$ decreased in early stationary phase cell extracts of mutant strain OB528 in which the hppA (oligopeptide-binding lipoprotein) gene was insertionally inactivated. This effect was correlated with proportionally reduced cell-surface expression of CshA protein and with impaired adherence of hppA mutant cells to cells of an oral Actinomyces naeslundii strain. cshA promoter activity was enhanced in streptococcal cells that were incubated in conditioned culture medium as opposed to fresh medium, but this did not occur in an hppA genetic background. It is suggested that HppA is necessary for the response of cells to an extracellular factor that modulates cshA transcription, and hence affects cell-surface CshA expression and streptococcal cell adherence properties.

Keywords: streptococcal cell adhesion, cell-surface proteins, oligopeptide permease, promoter activity, Streptococcus gordonii

\section{INTRODUCTION}

The ability of oral bacteria to adhere to components in the oral environment such as deposited salivary proteins and glycoproteins, host epithelial cell surfaces and other micro-organisms is critical to their growth and survival within the host. A large number of potential adhesins in oral bacteria have now been identified and characterized (reviewed by Whittaker et al., 1996) and the molecular complexities of these adhesion processes are becoming apparent. The adhesive and invasive properties of Grampositive bacteria, which comprise a large proportion of

†Present address: Department of Microbiology, Eastman Dental Institute, 256 Gray's Inn Road, London WC1X 8LD, UK.

¥Present address: Department of Oral and Dental Science, University of Bristol, Dental Hospital and School, Lower Maudlin Street, Bristol BS1 2LY, UK.

Abbreviation: CAT, chloramphenicol acetyltransferase.

The GenBank accession number for the cshA locus updated to include the upstream sequence is $\mathrm{X} 65164$. the human oral flora, are closely linked to the production of secreted proteins and activities of cell-wall-anchored polypeptides. The latter carry specialized sequences at their C-terminal regions that are necessary for polypeptide anchorage at the cell surface (Schneewind et al., 1995), and typically they contain repeat blocks of amino acid residues comprising up to $65 \%$ of the entire polypeptide (see Kehoe, 1994; Jenkinson \& Lamont, 1997). Both the amino acid residue repeat blocks and non-repetitive sequences within these proteins have been implicated in a wide range of colonization-associated reactions. These include, for example, the adhesion of streptococci and staphylococci to host tissue matrix components (Patti et al., 1994), resistance of group A streptococci to phagocytosis (Podbielski et al., 1996a), extracellular neuraminidase activity of pneumococci (Cámara et al., 1994), cell-surface hydrophobicity (Mc $\mathrm{Nab}$ et al., 1995) and adhesion of oral streptococci to salivary components and other oral bacterial cells (Jenkinson \& Demuth, 1997), and invasion of epithelial cells by Listeria monocytogenes (Lebrun et al., 1996). 
Gram-positive bacteria also express a second group of cell-surface-anchored proteins that are $\mathrm{N}$-terminally lipid-modified and thought to be linked to the outer face of the cytoplasmic membrane (Sutcliffe \& Russell, 1995). These lipoproteins function in transport processes such as solute uptake (Tam \& Saier, 1993) and in providing immunity to bacteriocins (de Vos et al., 1995). The best characterized are the substrate-binding lipoproteins of ATP-binding cassette (ABC)-type transport systems (Higgins, 1992) necessary for the uptake of peptides and oligopeptides (Alloing et al., 1994; Jenkinson et al., 1996; Kunji et al., 1996) and multiple sugars (Tao et al., 1993). There is additional evidence that these binding proteins may be involved in the adhesion of oral streptococci to salivary components (Ganeshkumar et al., 1991), fibrin (Burnette-Curley et al., 1995) and other oral bacteria (Kolenbrander et al., 1994).

Streptococcus gordonii is found at most sites within the human oral cavity (Frandsen $e t$ al., 1991) and exhibits a wide range of adherence properties. S. gordonii produces two high-molecular-mass cell-wall-anchored polypeptides designated CshA (predicted molecular mass $259 \mathrm{kDa}$ ) and CshB (approximate molecular mass $245 \mathrm{kDa}$ ) that are involved in determining cell-surface hydrophobicity (McNab et al., 1995), and that are essential for colonization of the oral cavity by $S$. gordonii (McNab et al., 1994). The CshA polypeptide mediates binding of $S$. gordonii cells to immobilized human fibronectin, Actinomyces naeslundii, Streptococcus oralis and Candida albicans (Holmes et al., 1996; $\mathrm{McNab}$ et al., 1996), and cshA mutants are deficient in binding to these substrates. Mutation in $b p p A$ encoding a substrate (oligopeptide)-binding protein of a hexaheptapeptide permease (Hpp) in S. gordonii (Jenkinson et al., 1996) also affects adhesion of streptococcal cells to oral $A$. naeslundii cells and human serum components (Jenkinson \& Easingwood, 1990).

To investigate the regulation of expression of CshA we constructed a fusion of the $\operatorname{csh} A$ gene promoter with a chloramphenicol acetyltransferase (cat) gene reporter. In this article, we show, by measuring CAT enzyme activities and cat mRNA levels, that the cshA promoter is most active during the late exponential phase of growth. Furthermore, transcription of the cshA gene and expression of associated adherence properties are dependent upon production of HppA.

\section{METHODS}

Bacterial strains and media. The bacterial strains and plasmids utilized are listed in Table 1 . Streptococci were grown at $37^{\circ} \mathrm{C}$ on TSBY agar (Jenkinson et al., 1993) in a GasPak System (BBL Microbiology Systems). Liquid cultures were grown without shaking in screw-cap tubes or bottles at $37^{\circ} \mathrm{C}$ in $\mathrm{BHY}$ medium (Jenkinson et al., 1993). Escherichia coli strains were grown aerobically at $37^{\circ} \mathrm{C}$ in LB medium (Sambrook et al., 1989). Concentrations of antibiotics used for selection were as follows: ampicillin, $100 \mu \mathrm{g} \mathrm{ml}^{-1}$ (E. coli); chloramphenicol, $5 \mu \mathrm{g} \mathrm{ml}^{-1}$ (E. coli); tetracycline, $15 \mu \mathrm{g} \mathrm{ml}^{-1}$ (E. coli) or $10 \mu \mathrm{g}$ $\mathrm{ml}^{-1}$ (S. gordonii); erythromycin, $50 \mu \mathrm{g} \mathrm{ml}^{-1}$ (E. coli) or $1 \mu \mathrm{g} \mathrm{ml}^{-1}$ (S. gordonii).
DNA manipulations. Routine molecular biology techniques were performed as specified by Sambrook et al. (1989). Plasmid DNA was isolated from E. coli by using Wizard Minipreps (Promega), and PCR products were purified by using QIAquick (Qiagen). Chromosomal DNA was isolated from $S$. gordonii as described previously (Jenkinson, 1987). S. gordonii cells were transformed with DNA according to Haisman \& Jenkinson (1991). Restriction and modifying enzymes (from New England BioLabs) were used under the conditions recommended by the manufacturer.

To obtain DNA sequence information $5^{\prime}$ to the ATG start codon of $c s h A$, inverse PCR was performed as outlined by McNab et al. (1994). Briefly, S. gordonii DL1 (Challis) genomic DNA was digested with PstI, self-ligated at $5 \mathrm{ng} \mathrm{\mu l}^{-1}$ and used as template in PCR (Expand High Fidelity System; Boehringer) with primers IPA (complementary to nucleotides 672-692, cshA locus; GenBank accession no. X65164), 5'CGAATAGAAAACTTACGCAGG-3', and IPB (nucleotides 926-946, cshA locus), 5'-ATACTGCACCTACAAACTCAG$3^{\prime}$ ( 30 cycles, $58^{\circ} \mathrm{C}$ primer annealing temperature). The PCR product $(2.04 \mathrm{~kb})$ was purified, and DNA fragments were subcloned in pUC19. DNA sequencing was performed with M13 forward or reverse primers or custom-synthesized oligonucleotides (DNA Express; Colorado State University) in an Applied Biosystems model 373A automated DNA sequencer, or manually using Sequenase (United States Biochemical). Sequence data were analysed with the University of Wisconsin Genetics Computer Group package (Devereux et al., 1984) and the BLAST algorithm (Altschul et al., 1990) was utilized for database searches.

Construction of the cshA promoter-cat fusion strain. To facilitate $\mathrm{PCR}$ product cloning into $\mathrm{pMH} 109$ which contains a promoterless Gram-positive cat gene (Hudson \& Stewart, 1986), restriction sites (underlined in the primer sequences below) were incorporated into the primers designed to amplify the $\operatorname{csh} A$ promoter region. The primer pair comprised SMAP1 (nucleotides 240-266, cshA locus), 5'-CTGCCCGGGATCGTGACTATCTATTTG- ${ }^{\prime}$, and SACP2 (complementary to nucleotides 619-645, cshA locus), 5'-AATGAGCTCCTATTTATTCATTATATT-3'. By using Expand System, a PCR product of the predicted size was amplified with 30 cycles and a primer annealing temperature of $58^{\circ} \mathrm{C}$. The PCR-amplified product $(405 \mathrm{bp}$ ) of $S$. gordonii DL1 chromosomal DNA containing the cshA promoter was digested with a combination of SmaI and SacI and ligated with pMH109 likewise digested. The ligation mixture was transformed into $E$. coli HB101 with selection for resistance to tetracycline and chloramphenicol. The recombinant pMH109 was then digested with $B a m H I$ to release a $1.3 \mathrm{~kb} c s h A$ promoter ( $p$ cshA)-cat fragment which was cloned into BamHI-cut pSF143 (Tao et al., 1992) to generate plasmid pSFCAT1. Plasmid pSFCAT1 was introduced onto the $S$. gordonii chromosome by transformation and selection for $\mathrm{Tc}^{\mathrm{R}}$ to generate recombinant strain OB507. The insertion also conferred resistance of $S$. gordonii to $1 \mu \mathrm{g}$ chloramphenicol $\mathrm{ml}^{-1}$. To confirm that the plasmid had integrated with insertion duplication of the target sequence at the predicted chromosomal region, nylon blots of HindIII-digested S. gordonii genomic DNAs were probed each with the labelled promoter PCR product and, separately, the BamHI fragment from pMH109 containing the cat gene.

To further ensure that the correct fusion construct on the streptococcal chromosome had been generated, an oligonucleotide primer, CATPCR [5'-AACACTAATATCAATTTCTGTGG-3' ${ }^{\prime}$; complementary to nucleotides $1348-1370$ of 
Table 1. Bacterial strains and plasmids used

\begin{tabular}{|c|c|c|}
\hline Strain/plasmid & Relevant characteristics & Reference/source \\
\hline \multicolumn{3}{|l|}{ Strains } \\
\hline \multicolumn{3}{|l|}{ S. gordonii } \\
\hline DL1 Challis & Wild-type & Pakula \& Walczak (1963) \\
\hline OB235 & cshA3::ermAM & McNab et al. (1994) \\
\hline OB285 & bppA1::ermAM & Jenkinson et al. (1996) \\
\hline OB423 & bppH2::ermAM* & This study \\
\hline OB507 & $p-c s h A-c a t ; \mathrm{Tc}^{\mathrm{R}}$ & This study \\
\hline OB528 & $\begin{array}{l}p \text {-cshA-cat hppA1::ermAM; } \mathrm{Tc}^{\mathrm{R}}(\mathrm{OB} 285 \\
\text { DNA } \rightarrow \text { OB } 507) \dagger\end{array}$ & This study \\
\hline OB568 & $\begin{array}{l}p-c s h A-c a t h p p H 2:: e r m A M ; \mathrm{Tc}^{\mathrm{R}}(\mathrm{OB} 423 \\
\text { DNA } \rightarrow \text { OB507) } \dagger\end{array}$ & This study \\
\hline OB587 & $\begin{array}{l}p \text {-cshA-cat cshA3::ermAM; } \mathrm{Tc}^{\mathrm{R}}(\mathrm{OB} 235 \\
\text { DNA } \rightarrow \text { OB507) }\end{array}$ & This study \\
\hline \multicolumn{3}{|c|}{ 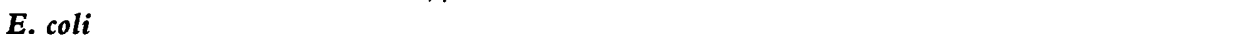 } \\
\hline HB101 & $\begin{array}{l}\mathrm{F}^{-} \Delta(g p t-p r o A) 62 \text { leuB6 supE44 ara-14 } \\
\text { galK2 lacY1 } \Delta(m c r C-m r r) \text { rpsL20 }\left(\mathrm{Str}^{\mathrm{R}}\right) \\
\text { xyl-5 mtl-1 recA13 }\end{array}$ & Boyer \& Roulland-Dussoix (1969) \\
\hline JM83 & $\begin{array}{l}\mathrm{F}^{-} \text {ara } \Delta(\text { lac-proAB) rpsL } \\
\left(\mathrm{Str}^{\mathrm{R}}\right)[\phi 80 \mathrm{~d} l a c \Delta(\text { lacZ) M15] thi }\end{array}$ & Yanisch-Perron et al. (1985) \\
\hline \multicolumn{3}{|l|}{ Plasmids } \\
\hline pUC19 & $2.68 \mathrm{~kb} ; \mathrm{Ap}^{\mathrm{R}}$ ColE1ori & Yanisch-Perron et al. (1985) \\
\hline pMH109 & $\begin{array}{l}7 \cdot 4 \mathrm{~kb} ; \mathrm{Tc}^{\mathrm{R}} \mathrm{Km}^{\mathrm{R}} \text { ColE1ori } \mathrm{pUB} 110 \text { ori, } \\
\text { promoterless cat gene }\end{array}$ & Hudson \& Stewart (1986) \\
\hline pSF143 & $5 \cdot 7 \mathrm{~kb} ; \mathrm{Tc}^{\mathrm{R}}$ pACYC184ori & Tao et al. (1992) \\
\hline
\end{tabular}

* OB423 is an $\mathrm{Em}^{\mathrm{R}}$ equivalent of OB427 hppH1:: tet (Jenkinson et al., 1996).

† Donor DNA $\rightarrow$ recipient strain by transformation.

the staphylococcal cat gene (GenBank accession number J01754)], was used for PCR with primer SMAP1 to amplify the promoter-cat fusion DNA region from OB507. The PCR product was sequenced directly using a cat-defined nested primer, CATSEQ (5'-CTAAAAGTCGTTTGTTGG-3'; complementary to nucleotides 1325-1342). For measurement of the effect of gene disruption on $c s h A$ promoter activity, mutations in $c s h A, h p p A$ or $h p p H$ genes were constructed by transformation of the $c s h A$ promoter-cat fusion strain OB507 (Table 1).

RNA analyses. Total RNA was prepared from $S$. gordonii cells by a modification of the method of Lunsford (1995). Streptococcal cells were grown in BHY medium $(20 \mathrm{ml})$ containing $10 \mu \mathrm{g}$ tetracycline $\mathrm{ml}^{-1}$ (BHY-Tc), harvested by centrifugation $\left(4000 \mathrm{~g}, 10 \mathrm{~min}, 4^{\circ} \mathrm{C}\right.$ ), washed once in diethyl pyrocarbonate (DEPC)-treated distilled $\mathrm{H}_{2} \mathrm{O}\left(\mathrm{dH}_{2} \mathrm{O}, 10 \mathrm{ml}\right)$ and suspended in spheroplasting buffer $(0.2 \mathrm{ml}$; Jenkinson et al., 1993) containing $0 \cdot 1 \mathrm{mg}$ spectinomycin $\mathrm{ml}^{-1}$. Mutanolysin (Sigma; final concentration $500 \mathrm{U} \mathrm{ml}^{-1}$ ) was added and the suspension was incubated at $37^{\circ} \mathrm{C}$ for $30 \mathrm{~min}$. Spheroplasts were collected by centrifugation $\left(5000 \mathrm{~g}, 10 \mathrm{~min}, 4^{\circ} \mathrm{C}\right)$, the supernatant was removed and discarded, and the spheroplasts were suspended in $1 \mathrm{ml}$ TriPure Isolation Reagent (Boehringer). RNA was purified according to the manufacturer's instructions, suspended in DEPC-treated $\mathrm{dH}_{2} \mathrm{O}$, and the concentration was determined by measuring the $A_{260}$ (Shimadzu).

For estimation of relative mRNA concentrations, total cell RNA samples $(50 \mu \mathrm{g})$ were denatured by heating (15 min, $\left.65^{\circ} \mathrm{C}\right)$ in the presence of formaldehyde $(7 \cdot 4 \%, \mathrm{w} / \mathrm{v})$ and $1 \times$ SSC $(0 \cdot 15 \mathrm{M} \mathrm{NaCl}, 0 \cdot 015 \mathrm{M}$ trisodium citrate; $\mathrm{pH} 7 \cdot 0)$. The solutions were diluted to $0 \cdot 1 \mu \mathrm{g} \mathrm{RNA} \mu^{-1}$ in $10 \times \mathrm{SSC}$ and diluted serially twofold in $10 \times$ SSC. Duplicate samples in the range $10-1 \cdot 25 \mu \mathrm{g}$ RNA were applied to nylon membrane held in a well-manifold, RNA was fixed to the membrane by UV treatment $(10 \mathrm{~min})$, and hybridization of blots with ${ }^{32} \mathrm{P}$ labelled cat gene fragment was performed as described by Church \& Gilbert (1984), with solutions containing $8 \%$ (w/v) dextran sulphate. Blots were washed three times each for 20 min with $2 \times \mathrm{SSC}$ containing $0.1 \%$ SDS at $65^{\circ} \mathrm{C}$. Relative RNA concentrations were quantified from laser densitometer scans of autoradiographs exposed for $48 \mathrm{~h}$ and expressed as mean peak height ( $\mu \mathrm{g}$ RNA $)^{-1}$ relative to the peak height ( $\mu \mathrm{g}$ RNA) ${ }^{-1}$ for an $S$. gordonii OB507 $16 \mathrm{~h}$ stationary phase sample.

Primer extension analysis. Purified RNA $(60 \mu \mathrm{g})$ was incubated for $15 \mathrm{~min}$ at $20^{\circ} \mathrm{C}$ with DNase I (2 U; amplification grade, Life Technologies), annealed with $1.6 \mathrm{pmol}^{32} \mathrm{P}-5^{\prime}$-endlabelled CATSEQ oligonucleotide in a final volume of $10 \mu \mathrm{l}$ $\mathrm{dH}_{2} \mathrm{O}$ by heating for $2 \mathrm{~min}$ at $80^{\circ} \mathrm{C}$ and allowing to cool slowly to room temperature. Primer extension was performed in the presence of RNAsin (10 U; Life Technologies) using Superscript II RNase $\mathrm{H}^{-}$reverse transcriptase (200 U; Life Technologies) $\left(50 \mathrm{~min}, 42^{\circ} \mathrm{C}\right)$. Reactions were heat-inactivated $\left(15 \mathrm{~min}, 70^{\circ} \mathrm{C}\right)$, cooled on ice and incubated for $20 \mathrm{~min}$ at $37^{\circ} \mathrm{C}$ with RNase $\mathrm{H}(2 \cdot 1 \mathrm{U}$; Life Technologies $)$. Extension products were ethanol-precipitated following phenol/ chloroform extraction, and analysed on an $8 \%$ poly- 
acrylamide sequencing gel adjacent to a sequence reaction for the relevant promoter-cat PCR product primed with the CATSEQ oligonucleotide.

Preparation of cell-free extracts and CAT assay. Streptococcal cells in BHY-Tc medium $(10 \mathrm{ml})$ were harvested by centrifugation $\left(4000 \mathrm{~g}, 10 \mathrm{~min}, 4^{\circ} \mathrm{C}\right)$ and washed once in TPE buffer

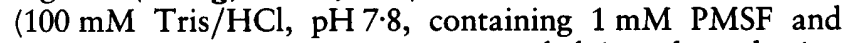
$1 \mathrm{mM}$ EDTA). Bacteria were suspended in spheroplasting buffer containing mutanolysin (see above) and incubated for $30 \mathrm{~min}$ at $37^{\circ} \mathrm{C}$. Cells were then disrupted by adding $0.4 \mathrm{ml}$ ice-cold TPE buffer and $0.1 \mathrm{ml}$ glass beads $(0.10 \mathrm{~mm}$ diameter $)$ and vortex mixing for two periods of $30 \mathrm{~s}$. Suspensions were centrifuged $\left(12000 \mathrm{~g}, 20 \mathrm{~min}, 4^{\circ} \mathrm{C}\right)$ to remove glass beads and cell debris, and supernatants were removed for enzyme assays. Protein concentrations were determined by using a Bio-Rad protein assay kit with bovine $\gamma$-globulin as the standard. CAT enzyme activity was determined by the spectrophotometric method of Shaw (1975), utilizing a Shimadzu UV-240 recording spectrophotometer with temperature-controlled cuvette chamber. The reaction rate was determined from the linear portion of the graph and corrected for background change in $A_{412}$, and divided by 0.0136 to yield CAT activity expressed as nmol chloramphenicol acetylated $\min ^{-1}$ at $37^{\circ} \mathrm{C}$.

Antibodies and ELISA. CshA-specific antibodies were raised to the $\mathrm{N}$-terminal non-repetitive amino acid sequence region of CshA (N-CshA; McNab et al., 1996) and used to determine the immunoreactivity of CshA present on intact streptococcal cells by ELISA (Holmes et al., 1995) utilizing an EL340 plate reader (Bio-Tek Instruments).

Bacterial adherence assays. Streptococci were radioactively labelled by growth in medium containing $\left[\right.$ methyl $\left.{ }^{3} \mathrm{H}\right]-$ thymidine $\left(0.22 \mathrm{MBq} \mathrm{ml}^{-1}, 3 \mathrm{TBq} \mathrm{mmol}^{-1}\right.$; Amersham). Adherence of streptococci to immobilized actinomyces cells was measured as described previously (Jenkinson et al., 1993). Statistical analysis. Student's $t$-test was used for all data and $P$ values $<0.05$ were considered significant.

\section{RESULTS}

\section{Sequence of the cshA gene promoter region}

The initial aim of this work was to identify factors regulating the expression of the $c s h A$ adhesin gene in $S$. gordonii, by utilizing a $c s h A$ promoter $(p-c s h A)-$ reporter gene fusion. Since sequence information was available for only seven nucleotides $5^{\prime}$ to the $c s h A$ start codon (McNab et al., 1994), upstream DNA was obtained by inverse PCR (see Methods). Nucleotide sequence data were obtained from a $2.04 \mathrm{~kb}$ amplimer that overlapped with previously reported $c s h A$ sequence (GenBank accession number X65164 updated to include upstream sequence). Computer analysis of the nucleotide sequence extending $645 \mathrm{bp}$ upstream of the $\operatorname{csh} A$ start codon predicted an open reading frame (nucleotides 1-313) encoding the C-terminal 104 aa residues of a polypeptide that exhibited $66 \%$ identity with $\alpha$ acetolactate decarboxylase (AldB) from Lactococcus lactis (GenBank accession number X82620) and 38\% identity with the homologous enzyme (AldC) from Bacillus subtilis (SWISS-PROT accession number Q04777). The aldB-cshA intergenic region in S. gordonii DL1 comprised 332 nucleotides (see Fig. 1). Between nucleotides 339 and 372 was a putative rho-independent transcriptional terminator predicted to form a stemloop structure. A potential RBS was identified six nucleotides upstream from the $\operatorname{csh} A$ translational start site (see Fig. 2). Two possible -10 promoter sequences (each TATAAT) were identified at 20 and 35 nucleotides $5^{\prime}$ to the $c s h A$ start codon, and a potential -35 sequence was located 18 nucleotides $5^{\prime}$ to the RBS distal -10 sequence (see Fig. 2).

(a)

(b)
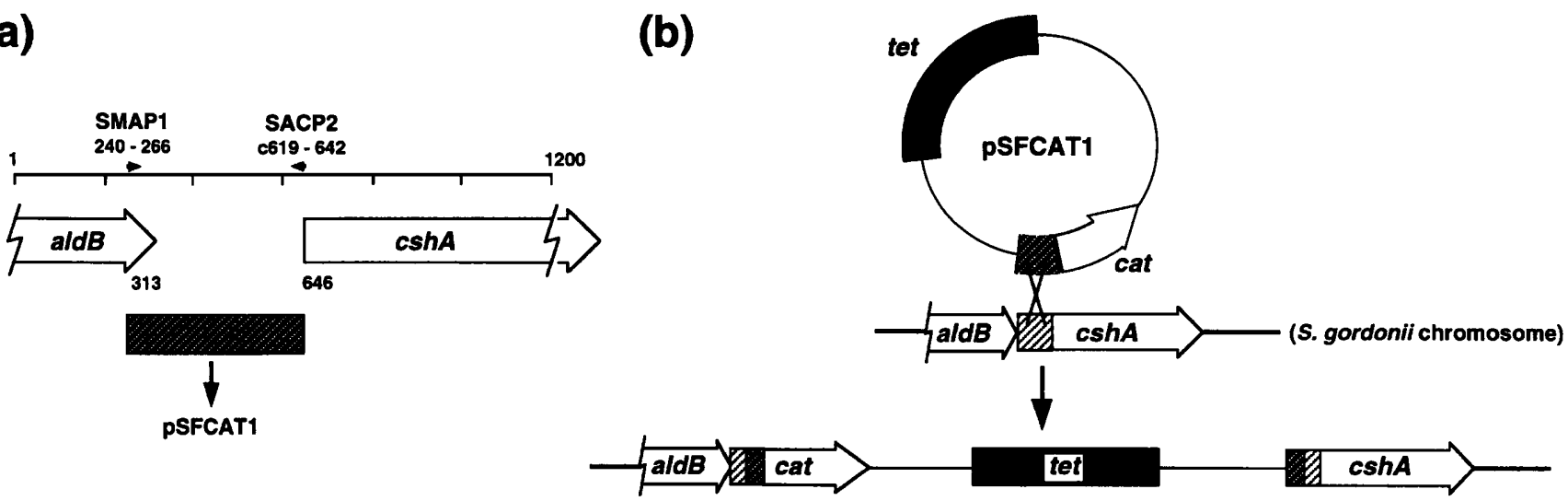

Fig. 1. Construction of the chromosomal cshA promoter-cat fusion. (a) Schematic diagram of the chromosomal region containing the cshA promoter. Numbers indicate base pairs from the start of the nucleotide sequence (in GenBank). The coding sequences for csh $A$ and $a / d B$ are indicated by open arrows, and the associated numbers delineate the coding sequences. Oligonucleotide primers (arrowed) were utilized in PCR to obtain a promoter-containing DNA fragment (dark hatching) that was cloned downstream of a promoterless cat gene in plasmid pSF143 to generate pSFCAT1 (see Methods). (b) Diagram depicting the introduction of the promoter-cat fusion onto the streptococcal chromosome by insertion duplication following recombination between the cloned promoter sequence (dark hatching) and the homologous chromosomal sequence (light hatching). The thick line represents $S$. gordonii chromosomal DNA, and the thin line represents PSF143 DNA. 


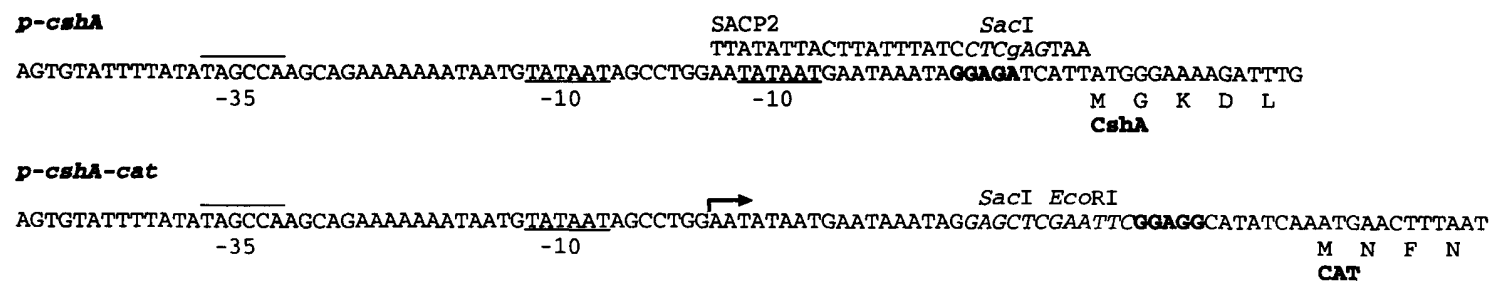

Fig. 2. Comparison of the sequence containing the cshA promoter region with the corresponding sequence generated by chromosomal promoter-cat fusion. SACP2 is the complementary strand oligonucleotide primer used for amplification of $p$-cshA sequence. Lower-case letters within the primer sequence indicate changes made from the chromosomal sequence that introduced a Sacl recognition site (given in italics) to facilitate cloning of the PCR product. Potential -10 (underscored) and -35 (overscored) promoter sequences are indicated, and RBS sequences are in bold type. The experimentally defined transcriptional start site for $p$-cshA-cat is indicated by an arrow.

\section{Construction of the cshA promoter-cat fusion}

A segment of $S$. gordonii chromosomal DNA (405 bp) containing $p$-cshA was obtained following PCR amplification (Fig. 1) and cloned $5^{\prime}$ to a promoterless cat gene present in plasmid pMH109 (Table 1). Since pMH109 contained an origin of replication that functioned in $S$. gordonii, the $p$-csh $A$-cat-containing fragment $(1.3 \mathrm{~kb})$ was excised and cloned into pSF143, which does not replicate in S. gordonii (Tao et al., 1992), to generate pSFCAT1 (Fig. 1). Plasmid pSFCAT1 was transformed onto the $S$. gordonii DL1 chromosome with selection for tetracycline resistance $\left(\mathrm{Tc}^{\mathbf{R}}\right)$ to generate strain $\mathrm{OB} 507$ containing an insertion duplication of the cshA promoters expressing cat (see Fig. 1b).

To check that the predicted promoter fusion had been obtained, PCR was used to amplify the corresponding chromosomal regions from $S$. gordonii OB507. The promoter fusion construct sequence obtained is shown in Fig. 2 and is aligned with the wild-type sequence. The RBS sequence for $c \operatorname{sh}$ (GGAGA) was replaced during construction of the promoter-cat fusion with the cat RBS sequence (GGAGG), and the RBS-ATG spacing was increased from five nucleotides to eight nucleotides. The $\operatorname{csh} A$ promoter region contained at least two potential -10 sequences (see Fig. 2). Therefore, primer extension was used to map the transcriptional start site of the gene by utilizing a cat-defined oligonucleotide (see Methods). A single primer extension product was obtained (Fig. 3). The $p$-cshA-cat mRNA initiated at nucleotide position -43 relative to the start codon of cat, equivalent to -27 nucleotides from the ATG start codon of $c s h A$ (Fig. 2).

\section{cshA promoter activity in cells at different stages of growth in batch culture}

To determine $c \operatorname{sh} A$ promoter activity at different stages of growth of $S$. gordonii cells in batch culture, strain OB507 ( $p-c s h A-c a t)$ was cultured in BHY-Tc medium and samples were taken at intervals for measurement of CAT activity in cell-free extracts. CAT enzyme activity within OB507 cultures increased throughout growth, lagging behind the growth curve, and reached a maximum at early stationary phase (Fig. 4).

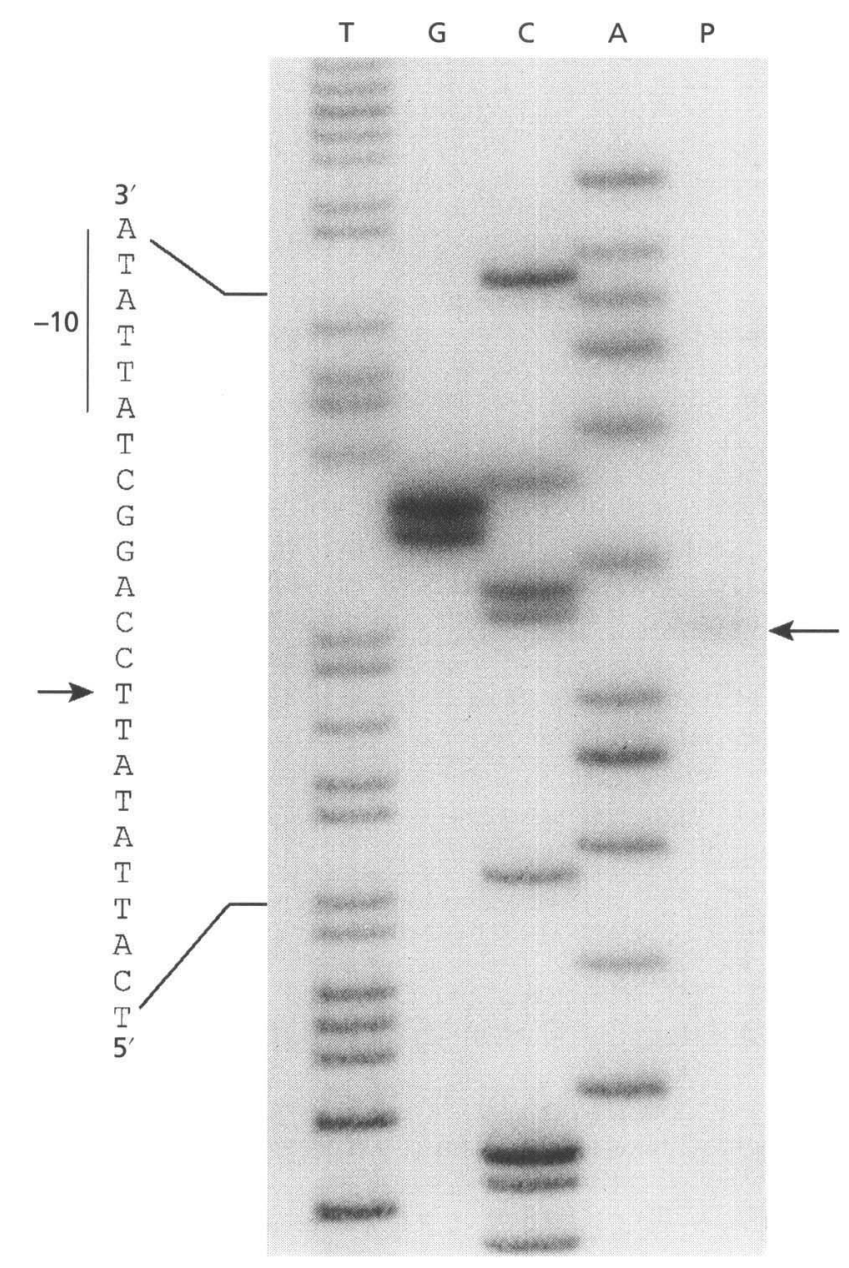

Fig. 3. Primer extension analysis of the transcriptional start point of $\operatorname{csh} A$. The extension reaction product is shown in lane $P$. The predicted transcriptional initiation site is indicated by an arrow in the expanded sequence on the left, which is the reverse complement of that shown in Fig. 2 . Sequences (lanes $T$, $G, C$ and $A$ ) were derived from the same CATSEQ primer utilized for the primer extension reaction.

To confirm that CAT enzyme activity was a direct estimate of promoter activity in $S$. gordonii, cat-specific mRNA present in extracts of $S$. gordonii OB507 cells 


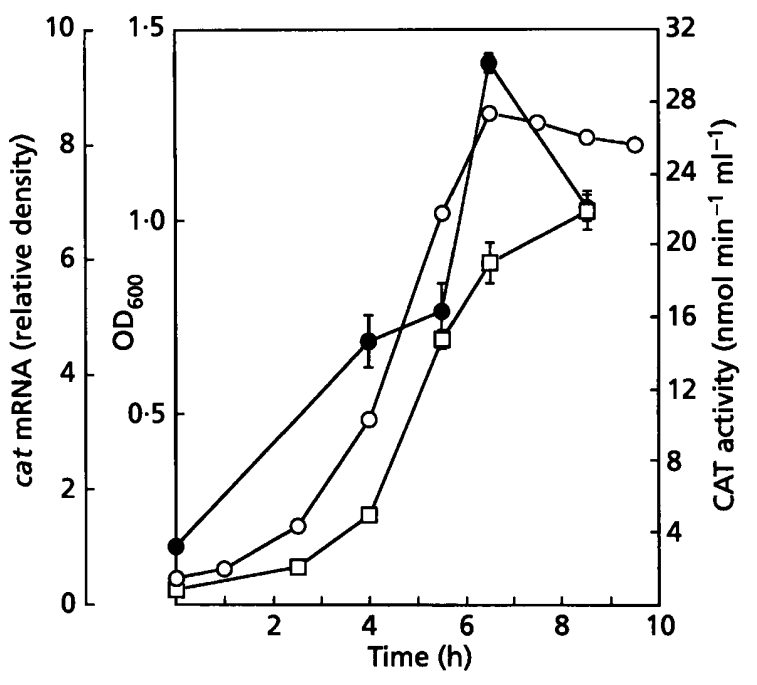

Fig. 4. Total culture CAT activity $(\square)$ and relative amount of cat mRNA (O) in cells of S. gordonii OB507 p-cshA-cat at points during growth in batch culture $\left(O\right.$; culture density at $\left.O_{600}\right)$. For each sample taken, a portion was utilized for CAT activity determination, while total RNA was prepared from the remainder for cat-specific mRNA determination by hybridization (see Methods). Results presented are from a representative experiment of four. Error bars are standard deviations of the mean of triplicate samples.

was quantified by blot hybridization analysis. RNA samples were reacted with a probe comprising the Bam HI fragment from pMH109 encoding the promoterless cat gene. cshA promoter activity as quantified by cat mRNA levels was found to be maximal at late exponential phase (Fig. 4). The continued increase in culture CAT activity that was associated with a decrease in catspecific mRNA level in early stationary phase cell extracts (Fig. 4) indicated that $c s h A$ gene expression continued well into stationary phase. The cshA promoter region contained a strong transcriptional terminator sequence upstream (data not shown), sug- gesting that transcriptional read-through of $\operatorname{csh} A$ from upstream was unlikely.

The growth-phase-related expression of CshA was examined in more detail for cells harvested at mid exponential phase (T1; Table 2 ) or at early stationary phase (T2; Table 2) of growth. The increased CAT specific activity of early stationary phase cell extracts compared with mid exponential phase cell extracts (50\% increase) correlated with an increased cell-surface expression of CshA ( $33 \%$ increase) as determined by ELISA, and with statistically significant $(P<0.005)$ improved adherence of cells to immobilized $A$. naeslundii WVU627 cells (Table 2).

\section{Effects of inactivating hppA on cshA gene expression}

It was demonstrated previously (see Introduction) that insertional inactivation of the $h p p A$ gene affected binding of $S$. gordonii cells to A. naeslundii (Jenkinson \& Easingwood, 1990), which is now known to be mediated, at least in part, by the CshA polypeptide ( $\mathrm{McNab}$ et al., 1996). To determine if inactivation of hppA affected $c s h A$ transcription, we measured specific CAT activity in cell extracts of strain OB528 ( $p$-cshAcat) in which $h p p A$ was insertionally inactivated (see Table 1). The CAT specific activity of mid exponential phase cell extracts of OB528 ( $h p p A)$ was reduced somewhat compared with extracts of cells of OB507 (wild-type) taken at the same time-point (Table 2). However, this was not associated with a significant difference in levels of adhesion of the two strains to $A$. naeslundii cells (Table 2). By early stationary phase of growth (T2 in Table 2), the expression of CAT enzyme activity from the $p$-csh $A-c a t$ promoter fusion in extracts of strain OB528 $(h p p A)$ was $28 \%$ less than that in OB507 (wild-type $\mathrm{HppA}^{+}$) extracts. This statistically significant $(P<0.0001)$ reduced CAT activity was associated with reduced cell-surface expression of CshA ( $P$ $<0.0001)$ and with impaired adhesion $(P<0.005)$ of cells to A. naeslundii WVU627 (Table 2). As a control

Table 2. Effect of inactivating cshA, hppA or hppH genes on cshA gene expression and adhesion of S. gordonii

Cells were harvested for analysis at mid exponential (T1) or early stationary (T2) phase of growth. Values are the means \pm SD of quadruplicate determinations from a representative experiment repeated three times. ND, Not determined.

\begin{tabular}{|c|c|c|c|c|c|c|}
\hline \multirow[t]{2}{*}{ Strain } & \multicolumn{2}{|c|}{$\begin{array}{c}\text { CAT specific activity } \\
{\left[\mathrm{nmol} \min ^{-1}(\mathrm{mg} \text { protein })^{-1}\right]}\end{array}$} & \multicolumn{2}{|c|}{$\begin{array}{c}\text { Amount of cell-surface CshA } \\
\text { antigen by ELISA* }\end{array}$} & \multicolumn{2}{|c|}{$\begin{array}{l}\text { Input cells } \dagger \text { attached to } A \text {. } \\
\text { naeslundii WVU627 (\%) }\end{array}$} \\
\hline & T1 & $\mathrm{T} 2$ & T1 & $\mathrm{T} 2$ & $\mathrm{~T} 1$ & $\mathbf{T} 2$ \\
\hline OB507 & $40.22 \pm 0.59$ & $60 \cdot 38 \pm 1 \cdot 52$ & $0.199 \pm 0.008$ & $0.265 \pm 0.007$ & $18.54 \pm 0.98$ & $28.46 \pm 3.04$ \\
\hline OB528 $h p p A$ & $35 \cdot 49 \pm 1 \cdot 30 \ddagger$ & $43 \cdot 64 \pm 0 \cdot 57 \ddagger$ & $0 \cdot 191 \pm 0 \cdot 008$ & $0.205 \pm 0.001 \ddagger$ & $16 \cdot 16 \pm 1 \cdot 76$ & $21 \cdot 38 \pm 1.58 \ddagger$ \\
\hline OB587 cshA & $41.61 \pm 0.99$ & $62.30 \pm 0.80$ & $0.008 \pm 0.002 \ddagger$ & $0.004 \pm 0.001 \ddagger$ & $12 \cdot 24 \pm 0.42 \ddagger$ & $14.90 \pm 1.74 \ddagger$ \\
\hline OB568 $h p p H$ & ND & $61.07 \pm 0.78$ & ND & $0.274 \pm 0.006$ & ND & ND \\
\hline
\end{tabular}

* N-CshA antibodies were diluted 1:2000 and ELISA values $\left(A_{492}\right)$ were corrected for values obtained with pre-immune serum (diluted $1: 2000)$.

†Input of $2 \times 10^{7}$ streptococcal cells.

$¥$ Significantly different from OB507 (wild-type) value within column, $P<0.05$. 
we also measured specific CAT activity of $S$. gordonii OB587 (cshA3) cells in which the chromosomal cshA gene was insertionally inactivated. As expected, these cells did not express CshA protein on their surfaces as determined by ELISA (Table 2), and they were approximately $50 \%$ reduced in adhesion (Table 2 ). However, specific CAT activities were similar to those present in OB507 (wild-type) cells at both time-points (Table 2); therefore it appears that expression of $c s h A$ does not normally modulate its own transcription. The 'residual' adhesion of $S$. gordonii OB587 (cshA3) cells to $A$. naeslundii, which is mediated primarily by SspA and SspB adhesins (see Jenkinson \& Demuth, 1997), increased slightly by early stationary phase, suggesting that expression of these adhesins may also be enhanced at this time. This may account, at least in part, for the increased adherence of $S$. gordonii OB528 ( $h p p A)$ stationary phase cells compared with mid exponential phase cells that was observed in the absence of a significant increase in CshA production (see Table 2).

To determine if the observed effects of inactivating the $h p p A$ gene were specific, we measured $c s h A$ expression in $S$. gordonii OB568 ( $p$-cshA-cat) in which the $h p p H$ gene was inactivated. Expression of the $h p p H$ gene is necessary for oligopeptide uptake via the Hpp transport system (Jenkinson et al., 1996), but $b p p H$ mutants, unlike $h p p A$ mutants, are unaffected in their adherence properties (R. A. Baker \& H. F. Jenkinson, unpublished data). The amounts of cell-surface CshA and specific CAT activity associated with early stationary phase OB568 $(h p p H)$ cells were found to be identical to those in OB507 (wild-type) (Table 2). This suggested that the previously observed effects of $h p p A$ gene inactivation on $c s h A$ transcription were specific to $h p p A$ and not simply due to inhibition of general oligopeptide uptake. Lastly, we determined that CAT enzyme activities were similarly stable in cell extracts from all the different strains, thus excluding the possibility that reduced specific CAT activities in OB528 ( $h p p A)$ extracts resulted from an increased rate of protein degradation.

\section{cshA expression is influenced by pre-conditioned culture medium}

The observation that $\operatorname{csh} A$ was maximally expressed in late exponential growth phase raised the possibility that an environmental cue and/or cell-density-related phenomenon might influence $c s h A$ promoter activity. In further support of this idea were the data showing the requirement of $\mathrm{HppA}$ for $c s h A$ expression, since $h p p A$ is essential for the natural development of competence (Jenkinson et al., 1996). This is a cell-density-associated event mediated in part by a sensor-regulator relay that is responsive to an extracellular peptide pheromone (Håvarstein et al., 1996). Therefore, to determine if $c s h A$ expression might be influenced by a quorum-associated factor, cells of $S$. gordonii OB507 (wild-type) in mid exponential phase of growth were harvested and suspended in either fresh medium or the medium from which they had been harvested (conditioned medium). After $2 \mathrm{~h}$ incubation there was $27 \%$ reduced $(P<0.001)$

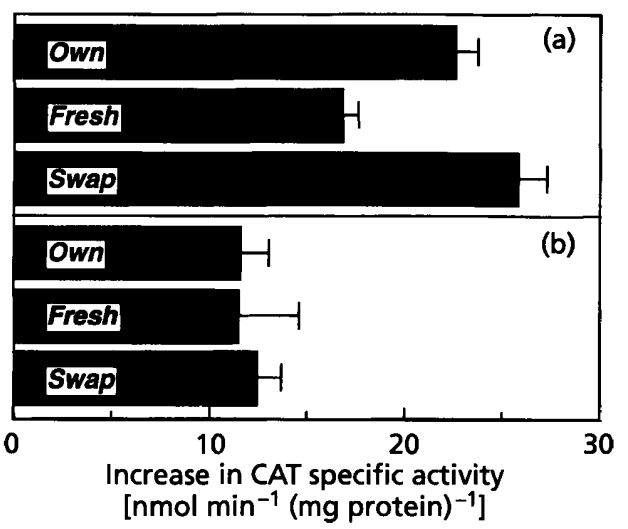

Fig. 5. Effect of pre-conditioned medium on p-cshA-cat activity. Mid exponential growth phase cultures of S. gordonii OB507 p-cshA-cat (a) or S. gordonii OB528 p-cshA-cat hppA1::ermAM (b) in BHY-Tc medium were divided into four equal portions and cells were harvested by centrifugation $(6000 \mathrm{~g}, 20 \mathrm{~min})$. One portion of cells was prepared for determination of CAT activity. Bacteria in the remaining portions were suspended at the original culture density in either conditioned medium from which they had been harvested (designated own in Figure), fresh BHY-TC (designated fresh) or in the conditioned cell-free culture medium from the opposing strain (designated swap). After incubating the cultures for $2 \mathrm{~h}$ at $37^{\circ} \mathrm{C}$, bacteria were harvested, cell-free extracts were prepared and specific CAT activities were determined. Results shown are from a representative experiment of four. Error bars are standard deviations of the mean of triplicate samples.

specific CAT activity associated with cells growing in fresh medium as compared with conditioned medium (Fig. 5). Conversely, in $h p p A$ mutant OB528 cells, cshA transcription, as measured by specific CAT activity, was similar in both fresh or conditioned media (Fig. 5). When cells of each strain were suspended in the opposing conditioned medium, identical results were obtained (Fig. 5). These observations are consistent with the idea that cells require HppA to respond to an extracellular factor that influences $c s h A$ gene expression. This putative factor was nonetheless still produced by OB528 $(h p p A)$ cells in which the $h p p A$ gene was inactivated (Fig. 5).

\section{DISCUSSION}

Streptococcal cells express multiple surface adhesins and some of these, such as CshA in S. gordonii, have multiple binding functions (see Jenkinson \& Lamont, 1997). CshA is involved in the determination of cellsurface hydrophobicity and adherence properties (Mc$\mathrm{Nab}$ et al., 1994, 1995) and mediates, in part, the binding of S. gordonii cells to fibronectin (McNab et al., 1996). To identify factors regulating expression of this important colonization factor we generated a $c s h A$ promoter-reporter gene fusion on the streptococcal chromosome. The cshA promoter was most active in late exponential phase cells as deduced by quantification of cat mRNA levels and measurement of CAT enzyme activity. Transcriptional mapping of the $c s h A$ promoter 
indicated that the RBS distal -10 sequence was likely to be active and this positioned a potential -35 sequence (TAGCCA) 18 nucleotides $5^{\prime}$ to the active -10 sequence. The $\operatorname{csh} A$ promoter sequences thus strongly resembled -35 and -10 consensus promoter sequences of E. coli (Hawley \& McClure, 1983) and proven promoter sequences in Streptococcus pneumoniae (Sabelnikov et al., 1995). They also matched, but not closely, the $s s p B$ adhesin gene promoter sequences in $S$. gordonii DL1 (Demuth et al., 1997). Neither the cshA nor $s s p B$ promoters appear to have extended -10 sequences, which are more frequently found in streptococcal gene promoters than in $E$. coli promoters (Sabelnikov et al., 1995).

The Hpp system in S. gordonii is involved in the uptake of larger oligopeptides (up to heptapeptides) and has three associated substrate-binding proteins designated HppA, HppG and HppH. Two of these three lipoproteins, HppA and $\mathrm{HppH}$, are essential for oligopeptide uptake (Jenkinson et al., 1996). Therefore, the observation that inactivation of $h p p A$, but not inactivation of $h p p H$, affected $c s h A$ expression suggests that the transcriptional effect was not due to inhibition of general peptide uptake. It is likely that $\mathrm{HppA}$ has some unique specificity for either substrate binding or other physiological response. Indeed, it has been shown that $\mathrm{HppA}$, but not $\mathrm{HppG}$ or $\mathrm{HppH}$, is necessary for the development of competence for transformation in $S$. gordonii (Jenkinson et al., 1996). The data presented in this article suggest that $\mathrm{HppA}$ might be involved in sensing extracellular signals that not only modulate competence development in $S$. gordonii but also expression of the $\operatorname{csh} A$ adhesin gene. Evidence for an extracellular signal is provided by the experiments in which $c s h A$ expression was shown to be repressed in exponential phase cells suspended in fresh culture medium compared with cells suspended in conditioned medium. The $c s h A$ promoter in $h p p A$ mutant cells failed to respond to conditioned medium, although an $h p p A$ mutant was still capable of conditioning the medium that subsequently effected a $p$-csh $A$ response in an $\mathrm{HppA}^{+}$background. In light of the evidence that the transport preference of the Hpp system is for oligopeptides of 5-7 aa residues (Jenkinson et al., 1996), it would seem most likely that the putative extracellular factor is an oligopeptide. In this respect, it is significant that the competence-stimulating factor recognized by Spo0K (oligopeptide permease) in $B$. subtilis is a pentapeptide (Solomon et al., 1996), conjugative transfer of plasmid pCF10 by Enterococcus faecalis donor cells occurs as a result of uptake of a heptapeptide pheromone secreted by recipient cells (Leonard et al., 1996), and an octapeptide pheromone modulates late exponential phase expression of Staphylococcus aureus virulenceassociated genes ( $\mathrm{Ji}$ et al., 1995). By utilizing the promoter fusion constructs described in this article we hope to identify the extracellular factor that stimulates $\operatorname{csh} A$ promoter activity in $S$. gordonii. It is worth emphasizing that these data demonstrate that only relatively small differences in $\operatorname{csh} A$ promoter activity appear sufficient to cause significant affects on cell adhesion properties. The growth-phase-related modulatory effects on CshA production are clearly distinct from other induction systems that may lead to anywhere between severalfold to thousandfold increases in transcript levels. The modulation of $c \operatorname{sh} A$ promoter activity described is reminiscent of the approximately $50 \%$ increase in expression of $g t f B C$ genes, encoding glucosyltransferases $B$ and $C$ synthesizing extracellular glucans, that was associated with adherent as opposed to non-adherent cells of Streptococcus mutans (Hudson \& Curtiss, 1990).

Oligopeptide transport systems in Gram-positive bacteria are essential for the uptake of peptides as sources of nutrients, but evidence has accumulated suggesting they are involved in determining other critical cellular functions and properties. These include the development of competence (Pearce et al., 1994; Alloing et al., 1996; Jenkinson et al., 1996), and the expression of virulence and adhesion properties of streptococci; for example, inactivating the oligopeptide permease of Streptococcus pyogenes affects production of secreted proteins and reduces expression of extracellular cysteine protease, a major virulence factor (Podbielski et al., 1996b). In particular though, the activities of peptide permeases have been linked consistently with expression of streptococcal adherence properties: thus, inactivation of $h p p A$ affects adherence and aggregation properties of $S$. gordonii (Jenkinson \& Easingwood, 1990), while mutations in ami genes reduce the ability of pneumococcal cells to adhere to human epithelial and endothelial cells (Cundell et al., 1995). These studies raised the possibility that oligopeptide permease proteins had dual functions in substrate binding and adherence. In light of the results presented in this article, it is likely that the reduced adherence properties demonstrated by $h p p A$ mutants of $S$. gordonii are due to, at least in part, reduction in transcriptional activity of the $c s h A$ promoter and thus reduced cell-surface expression of a major adhesin.

\section{ACKNOWLEDGEMENTS}

We thank R. D. Lunsford and L. Tao for the gifts of plasmids. We also thank R. A. Baker and A. R. Young for skilled technical assistance, and A. R. Holmes for helpful discussions. This work was supported by the Health Research Council of New Zealand.

\section{REFERENCES}

Alloing, G., de Philip, P. \& Claverys, J.-P. (1994). Three highly homologous membrane-bound lipoproteins participate in oligopeptide transport by the ami system of gram-positive Streptococcus pneumoniae. J Mol Biol 241, 44-58.

Alloing, G., Granadel, C., Morrison, D. A. \& Claverys, J.-P. (1996). Competence pheromone, oligopeptide permease, and induction of competence in Streptococcus pneumoniae. Mol Microbiol 21, 471-478.

Altschul, S. F., Gish, W., Miller, W., Myers, E. W. \& Lipman, D. J. (1990). Basic local alignment search tool. J Mol Biol 215, 403-410.

Boyer, H. W. \& Roulland-Dussoix, D. (1969). A complementation 
analysis of the restriction and modification of DNA in Escherichia coli. J Mol Biol 41, 459-472.

Burnette-Curley, D., Wells, V., Viscount, H., Munro, C. L., Fenno, J. C., Fives-Taylor, P. \& Macrina, F. L. (1995). FimA, a major virulence factor associated with Streptococcus parasanguis endocarditis. Infect Immun 63, 4669-4674.

Cámara, M., Boulnois, G. J., Andrew, P. W. \& Mitchell, T. J. (1994). A neuraminidase from Streptococcus pneumoniae has the features of a surface protein. Infect Immun 62, 3688-3695.

Church, G. M. \& Gilbert, W. (1984). Genomic sequencing. Proc Natl Acad Sci USA 81, 1991-1995.

Cundell, D. R., Pearce, B. J., Sandros, J., Naughton, A. M. \& Masure, H. R. (1995). Peptide permeases from Streptococcus pneumoniae affect adherence to eukaryotic cells. Infect Immun 63, 2493-2498.

Demuth, D. R., Duan, Y., Jenkinson, H. F., McNab, R., Gil, S. \& Lamont, R. J. (1997). Interruption of the Streptococcus gordonii M5 $s s p A / s s p B$ intergenic region by an insertion sequence related to IS1167 of Streptococcus pneumoniae. Microbiology 143, 2047-2055.

Devereux, J., Haeberli, P. \& Smithies, O. (1984). A comprehensive set of sequence analysis programs for the VAX. Nucleic Acids Res 12, 387-395.

Frandsen, E. V. G., Pedrazzoli, V. \& Kilian, M. (1991). Ecology of viridans streptococci in the oral cavity and pharynx. Oral Microbiol Immunol 6, 129-133.

Ganeshkumar, N., Hannam, P. M., Kolenbrander, P. E. \& McBride, B. C. (1991). Nucleotide sequence of a gene coding for a salivabinding protein $(\mathrm{SsaB})$ from Streptococcus sanguis 12 and possible role of the protein in coaggregation with actinomyces. Infect Immun 59, 1093-1099.

Haisman, R. J. \& Jenkinson, H. F. (1991). Mutants of Streptococcus gordonii Challis overproducing glucosyltransferase. J Gen Microbiol 137, 483-489.

Håvarstein, L. S., Gaustad, P., Nes, I. F. \& Morrison, D. A. (1996). Identification of the streptococcal competence pheromone receptor. Mol Microbiol 21, 863-869.

Hawley, D. K. \& McClure, W. R. (1983). Compilation and analysis of Escherichia coli promoter DNA sequences. Nucleic Acids Res 11, 2237-2255.

Higgins, C. F. (1992). ABC transporters: from microorganisms to man. Annu Rev Cell Biol 8, 67-113.

Holmes, A. R., Gopal, P. K. \& Jenkinson, H. F. (1995). Adherence of Candida albicans to a cell surface polysaccharide receptor on Streptococcus gordonii. Infect Immun 63, 1827-1834.

Holmes, A. R., McNab, R. \& Jenkinson, H. F. (1996). Candida albicans binding to the oral bacterium Streptococcus gordonii involves multiple adhesin-receptor interactions. Infect Immun 64, 4680-4685.

Hudson, M. C. \& Curtiss, R., III (1990). Regulation of expression of Streptococcus mutans genes important to virulence. Infect Immun 58, 464-470.

Hudson, M. C. \& Stewart, G. C. (1986). Differential utilization of Staphylococcus aureus promoter sequences by Escherichia coli and Bacillus subtilis. Gene 48, 93-100.

Jenkinson, H. F. (1987). Novobiocin-resistant mutants of Streptococcus sanguis with reduced cell hydrophobicity and defective in coaggregation. J Gen Microbiol 133, 1909-1918.

Jenkinson, H. F. \& Demuth, D. R. (1997). Structure, function and immunogenicity of streptococcal antigen I/II polypeptides. Mol Microbiol 23, 183-190.
Jenkinson, H. F. \& Easingwood, R. A. (1990). Insertional inactivation of the gene encoding a 76-kilodalton cell-surface polypeptide in Streptococcus gordonii Challis has a pleiotropic effect on cell surface composition and properties. Infect Immun 58, 3689-3697.

Jenkinson, H. F. \& Lamont, R. J. (1997). Streptococcal adhesion and colonization. Crit Rev Oral Biol Med 8, 175-200.

Jenkinson, H. F., Terry, S. D., McNab, R. \& Tannock, G. W. (1993). Inactivation of the gene encoding surface protein SspA in Streptococcus gordonii DL1 affects cell interactions with human salivary agglutinin and oral actinomyces. Infect Immun 61, 3199-3208.

Jenkinson, H. F., Baker, R. A. \& Tannock, G. W. (1996). A bindinglipoprotein-dependent oligopeptide transport system in Streptococcus gordonii essential for uptake of hexa- and heptapeptides. J Bacteriol 178, 68-77.

Ji, G., Beavis, R. C. \& Novick, R. P. (1995). Cell density control of staphylococcal virulence mediated by an octapeptide pheromone. Proc Natl Acad Sci USA 92, 12055-12059.

Kehoe, M. A. (1994). Cell-wall-associated proteins in grampositive bacteria. In Bacterial Cell Wall, pp. 217-261. Edited by J.-M. Ghuysen \& R. Hakenbeck. London: Elsevier.

Kolenbrander, P. E., Andersen, R. N. \& Ganeshkumar, N. (1994). Nucleotide sequence of the Streptococcus gordonii PK488 coaggregation adhesin gene, scaA, and ATP-binding cassette. Infect Immun 62, 4469-4480.

Kunji, E. R. S., Mierau, I., Hagting, A., Poolman, B. \& Konings, W. N. (1996). The proteolytic systems of lactic acid bacteria. Antonie Leeuwenboek 70, 187-221.

Lebrun, M., Mengaud, J., Ohayon, H., Nato, F. \& Cossart, P. (1996). Internalin must be on the bacterial surface to mediate entry of Listeria monocytogenes into epithelial cells. Mol Microbiol 21, 579-592.

Leonard, B. A. B., Podbielski, A., Hedberg, P. J. \& Dunny, G. M. (1996). Enterococcus faecalis pheromone binding protein, $\operatorname{PrgZ}$, recruits a chromosomal oligopeptide permease system to import sex pheromone cCF10 for induction of conjugation. Proc Natl Acad Sci USA 93, 260-264.

Lunsford, R. D. (1995). Recovery of RNA from oral streptococci. BioTechniques 18, 412-413.

McNab, R., Jenkinson, H. F., Loach, D. M. \& Tannock, G. W. (1994). Cell-surface-associated polypeptides CshA and CshB of high molecular mass are colonization determinants in the oral bacterium Streptococcus gordonii. Mol Microbiol 14, 743-754.

McNab, R., Holmes, A. R. \& Jenkinson, H. F. (1995). Cell-surface polypeptides as determinants of hydrophobicity in Streptococcus gordonii and Streptococcus sanguis. Colloids Surf 5, 135-142.

McNab, R., Holmes, A. R., Clarke, J. M., Tannock, G. W. \& Jenkinson, H. F. (1996). Cell surface polypeptide CshA mediates binding of Streptococcus gordonii to other oral bacteria and to immobilized fibronectin. Infect Immun 64, 4204-4210.

Pakula, R. \& Walczak, W. (1963). On the nature of competence of transformable streptococci. J Gen Microbiol 31, 125-133.

Patti, J. M., Allen, B. L., McGavin, M. J. \& Hobk, M. (1994). MSCRAMM-mediated adherence of microorganisms to host tissues. Annu Rev Microbiol 48, 585-617.

Pearce, B. J., Naughton, A. M. \& Masure, H. R. (1994). Peptide permeases modulate transformation in Streptococcus pneumoniae. Mol Microbiol 12, 881-892.

Podbielski, A., Schnitzler, N., Beyhs, P. \& Boyle, M. D. P. (1996a). 
M-related protein (Mrp) contributes to group A streptococcal resistance to phagocytosis by human granulocytes. Mol Microbiol 19, 429-441.

Podbielski, A., Pohl, B., Woischnik, M., Körner, C., Schmidt, K.-H., Rozdzinski, E. \& Leonard, B. A. B. (1996b). Molecular characterization of group A streptococcal (GAS) oligopeptide permease (Opp) and its effect on cysteine protease production. Mol Microbiol 21, 1087-1099.

Sabelnikov, A. G., Greenberg, B. \& Lacks, S. A. (1995). An extended -10 promoter alone directs transcription of the DpnII operon of Streptococcus pneumoniae. J Mol Biol 250, 144-155.

Sambrook, J., Fritsch, E. F. \& Maniatis, T. (1989). Molecular Cloning: a Laboratory Manual, 2nd edn. Cold Spring Harbor, NY: Cold Spring Harbor Laboratory.

Schneewind, O., Fowler, A. \& Faull, K. F. (1995). Structure of the cell wall anchor of surface proteins in Staphylococcus aureus. Science 268, 103-106.

Shaw, W. V. (1975). Chloramphenicol acetyltransferase from chloramphenicol-resistant bacteria. Methods Enzymol 43, 737755.

Solomon, J. M., Lazazzera, B. A. \& Grossman, A. D. (1996). Purification and characterization of an extracellular peptide factor that affects two different developmental pathways in Bacillus subtilis. Genes Dev 10, 2014-2024.
Sutcliffe, I. C. \& Russell, R. R. B. (1995). Lipoproteins of grampositive bacteria. J Bacteriol 177, 1123-1128.

Tam, R. \& Saier, M. H., Jr (1993). Structural, functional, and evolutionary relationships among extracellular solute-binding receptors of bacteria. Microbiol Rev 57, 320-346.

Tao, L., LeBlanc, D. J. \& Ferretti, J. J. (1992). Novel streptococcalintegration shuttle vectors for gene cloning and inactivation. Gene 120, 105-110.

Tao, L., Sutcliffe, I. C., Russell, R. R. B. \& Ferretti, J. J. (1993). Transport of sugars, including sucrose, by the $m s m$ system of Streptococcus mutans. J Dent Res 72, 1386-1390.

de Vos, W. M., Kuipers, O. P., van der Meer, J. R. \& Siezen, R. J. (1995). Maturation pathway of nisin and other lantibiotics : posttranslationally modified antimicrobial peptides exported by gram-positive bacteria. Mol Microbiol 17, 427-437.

Whittaker, C. J., Klier, C. M. \& Kolenbrander, P. E. (1996). Mechanisms of adhesion by oral bacteria. Annu Rev Microbiol 50, 513-552.

Yanisch-Perron, C., Vieira, J. \& Messing, J. (1985). Improved M13 phage cloning vectors and host strains: nucleotide sequences of the M13mp18 and pUC19 vectors. Gene 33, 103-119.

Received 30 June 1997; revised 5 September 1997; accepted 12 September 1997. 